\title{
The Group Discussion ‘Practical Possibilities of Taking Living Wills into Consideration'
}

This is a translation of a discussion held in the Estonian language on 31 May 2017. The group discussion transcribed here, with explanatory footnotes provided by Mari Lõhmus, was led by Tarvo Puri, a notary in Tallinn.

\section{Participants:}

Helgi Kolk - attending physician and lecturer at the Department of Traumatology and Orthopaedics of Tartu University Hospital, and President of the Estonian Association of Gerontology and Geriatrics

Teija Toivari - Nursing Director for the Tallinn Diaconal Hospital Hospice Department

Mari Lõhmus - oncologist with the Chemotherapy Stationary Department and consultant with the Palliative Care Service of the North Estonia Medical Centre

Liidia Meel - doctoral student with the School of Theology and Religious Studies at the University of Tartu Rainis Int - notary in Tallinn

Tarvo Puri: Let's talk about whether and to what extent anyone here in Estonia has had experience with the topic of taking the patient's wishes into consideration. Have these wishes been written down, are they noted somewhere in digital medical files, and are these topics discussed with a patient - and in what cases?

Helgi Kolk: The prerequisite for any kind of medical treatment is consent: informed consent of the patient. How it is given or received is an entirely different issue. In a trauma unit, where the patients come in with emergencies, they usually have no prior wishes registered. I deal mostly with elderly patients with serious trauma, severe bone fractures. We often have to decide whether to even operate or how to proceed. In reality, there is no-one to ask, because about a third of the patients we see have either a milder or more severe form of dementia and are unable to make adequate decisions. Common practice in such cases is to look for children and caregivers. We hardly ever encounter guardianship over people with dementia. Guardianship can be implemented when serious but non-urgent decisions need to be taken in a hospital setting. In reality, we have a really hard time finding out about consent.

Mari Lõhmus: It's everyday practice that patients and their loved ones are consulted with regard to their wishes and will. This depends on the care plan. For us in oncology, however, the dimension of time may be somewhat different: we have time to discuss and reflect on things, often discussing matters of treatment and ceasing it. Decision cases in which the patients themselves have written down their wishes are extremely rare. This information is hardly ever in health files either. In day-to-day practice, we write down patients' decisions to voluntarily refuse treatment or to end it, so that we would have at least some sort of legal grounds or decision to refer to, should that be necessary later.

Tarvo Puri: So there have been talks with patients on ending treatment under certain circumstances?

Mari Lõhmus: There comes a point with any patient when treatment has to be stopped. It is done less in Estonia, but care plans are prepared further ahead in oncology abroad. As soon as it becomes clear that, while the cancer is not treatable, there are numerous end-of-life care options at the moment of diagnosis, we start discussing the options and talk about what to do when the options run out - what the patient's wishes are in such a situation. I think that is done more and more these days. But we don't have a document in which the patient's wishes are written down or registered. There is no advance care plan ${ }^{{ }^{*}}$ used in Estonia.

1 Instructions for future treatment and care. 
Teija Toivari: The people ending up in our hospice ${ }^{*_{2}}$ are mostly cancer patients at the end of their life. Let's just say that in the 15 years we've been operating, things have improved. More recently there have been discussions with patients about stopping treatment. However, there are still people who end up in the hospice without being sure whether their treatment will continue or not. Relatives may have different expectations than patients. For instance, there is saattohoitopäätös in Finland - at one point, a decision is made that this is the end of active treatment ${ }^{*} 3$ and it is replaced with palliative care ${ }^{*} 4$ until the end of the person's life. That is a much simpler way - if the patient ends up in an ER or someplace similar, the staff know that they should not resuscitate. We would not take such aggressive medical measures to preserve a life as would, in reality, bring nothing but suffering to the patient.

The second place where we feel the lack of guidance sharply is in the case of people who still have weeks, maybe even months, to live - for instance, with a brain tumour. They can no longer express their wishes themselves or say what they want. Relatives may have disagreements. Some may completely accept the situation; others would still like to send the patient for further tests and conclude that the treatment should continue. Some would like us to introduce a sound in the event that the patient loses the ability to swallow independently. Sometimes we as employees see all this and think to ourselves that if we were in the patient's shoes we'd probably not want this. In that case, there's nothing more we can do than try to talk with the loved ones. How well that turns out is a completely different issue. There may be problems, complaints later. This issue always remains.

Liidia Meel: This is often so difficult for the loved ones - emotionally, morally, and also with regard to knowledge. Hospital workers - nurses and doctors - often lack emotional or social preparation that helps them support the family and friends in the decision-making process. For example, the Facilitated Values History has been proposed in international discussion. Narratives from the family and friends of the patient are used to gather information about the patient as a person: what was important to him or her throughout his or her life. For the patient, this means dignity at the end of life. In which this dignity is seen, varies. Such a framework would help both staff and loved ones, because decisions by family and friends may be made on the basis also of the initial emotion, in attempts to keep the person alive for as long as possible, while only later are they able to see what was important for the patient.

Tarvo Puri: Let's take a look at a scenario that is relatively uncommon in Estonia - the patient has written down how he or she should be treated or in what case treatment should be stopped. Are doctors taking this into consideration in Estonia right now?

Mari Lõhmus: If the wishes expressed in writing are clinically adequate and understandable and are in accordance with a doctor's opinion as to what might be in the best interest of the patient, then yes, I do believe that doctors will try to take these decisions into account. Where the means exist - i.e., there are financial and technical possibilities provided by the Health Insurance Fund - they are taken into consideration. On the other hand: is the information given by the patient about the treatment oral or written? There is probably greater reason to believe that the decision has been given more thought when it is written down in a document. But we nevertheless consider the verbal wishes of the patients, just the same.

Tarvo Puri: In that case, yes, if that particular doctor has an opportunity to discuss these matters with the patient. What I was referring to is the situations wherein the patient is no longer able to communicate no contact can be made - but the patient has a paper with him or her that states a decision not to be treated.

Helgi Kolk: By the way, such papers do exist. For instance, we have Jehovah's Witnesses. When these people end up in A\&E, they have a very categorical request that no blood transfusions be given. But that is often necessary, even before surgery. The other thing is that for major surgery we cannot accept a patient who has not consented to blood transfusions, because that need may arise either during or after the surgery. Although I teach second-year students in the ethics course that the patient's wish is a command and there is no place for paternalism - a situation in which doctors choose to make the decisions because they 'know better' and assume that the other party does not - I'll be honest with you: in the case of those elderly people, we really don't know what's best. When we see that the patient would definitely benefit from the surgery - that is, that the patient will likely become mobile again, while not operating would mean him or

2 A hospital that is guided by hospice philosophy and follows the generally recognised values in care, among them human rights, human dignity, equality, equal rights, the right of self-determination, and freedom to decide. The focus of a hospice is on ensuring a person's holistic treatment, also at the end of life.

3 Specific treatment of illnesses.

4 Here, in the sense of palliative and symptom-relieving care. 
her remaining immobile - I have obtained a signature from the patient, explaining that we do blood transfusions only when vitally necessary. Transfusions aren't always necessary; it's just that we need to have a guarantee because we can't let the patient bleed to death. In that case, this is what we have to do - trick them a little bit. It can be a matter of ethics if we go against the person's religious principles: how strong is that faith, and how strong is the will to survive? And when the patients survive, do they want to remain bedridden or start walking again - for instance, after a femur fracture? These are the choices we have to make.

Tarvo Puri: Yes, such internal conviction may be formed on religious grounds. Or a person may arrive at it through his or her personal decisions, however.

Helgi Kolk: Yes, but we as doctors talk them into things by using certain arguments, and that is not entirely medically ethical. Or we just claim that we perform a blood transfusion only if it is a matter of life or death. In general, that is, of course, true, but, on the other hand, we should accept that if a person says no, it's a no. After all, that's the way it is. If it is put down in writing and they always carry the document with them, it's a matter of accepting the person's decision.

Tarvo Puri: Here's another question stemming from that. Do they use any specific forms?

Helgi Kolk: Yes, they have special forms with all the information. It's printed text. I believe it's the same for everyone.

Tarvo Puri: What is the experience of others with handling such documents?

Teija Toivari: I can't remember having seen them. But an occasion on which it would be really good to have it is when - in hospice, such a moment is critical - the patient no longer swallows, when the patient's condition has become that severe. It's then when we need to ask whether to continue with drip infusion ${ }^{*}$, insert a probe, or just leave the person be. These are truly complicated moments. If we had a paper stating the patient's wish that no such things be used but it wasn't legally valid, a lot depends on the relatives in terms of whether we would dare to act on the basis of that paper or not.

Tarvo Puri: The most important decision would definitely be whose opinion matters the most. If a patent who no longer speaks expressed his or her wishes earlier, should that decision be the one to consider, or the opinion of the relatives who are sitting around the bed at the hospital?

Helgi Kolk: This is a really important issue, truly. If we were to actually start making these living wills or health wills, it would be vital for the person to decide who will be the one to make the decision, because that is the key issue. Relatives often have very different, downright diametrically opposed interests. One day, we reach a decision that further action (that is, surgery) is too risky and would not improve the person's quality of life. But the next day, the management of the clinic have received a phone call: 'Can you believe that? They didn't even operate!' There is no way of asking the patient's own opinion. And then the relatives start fighting amongst themselves and...

Teija Toivari: Exactly. That's why it would be great if the patient's wishes were official. It would also give the patients a sense of certainty that we are able to act in accordance with their wishes.

Helgi Kolk: For instance, two weeks ago I had a situation in which a man had gangrene affecting his leg and a chronic mental disorder rendered him incapable of exercising his own will. The foot needed to be amputated. Consent was requested from his estranged wife, with whom there hadn't been an official divorce. She did not give permission to amputate. The man was in unbearable pain - we had no analgesics to relieve it with - but you cannot amputate without permission. Finally, the staff managed to talk to her enough to get her to finally agree.

Mari Lõhmus: Situations like that are highly complicated emotionally. It is better to make the decisions beforehand than to start deciding in a crisis situation or at such complicated times as the death or severe illness of a loved one. Even if these topics are extremely complicated or unpleasant to discuss because the entire illness, especially death, may be a taboo topic, the experience of other countries shows that the sooner these difficult topics are discussed, the better, as opposed to handling the situation later.

Tarvo Puri: Could this discussion be held between a doctor and future patients, then? They may not even have a specific health problem just yet. In some countries, when people reach a certain age, they are told it's time to let others know about their decisions on these matters.

Helgi Kolk: It should be discussed with the family doctor. People are used to turning to doctors throughout life. Everyone has a family doctor, but probably not everyone has a personal notary.

$5 \quad$ Intravenous fluid-replacement treatment. 
Liidia Meel: In a hospital, a doctor should be sufficiently informed and prepared to be able to communicate and direct attention to these matters while being able to refer the patient to other specialists. The doctor shouldn't be the only one to consult with. Maybe the topics that need more attention are in the domain of social work, having something to do with psychology or faith.

Tarvo Puri: So we have two points of choice here now. One of them is that the person expresses - the simplest way would be to do it via some sort of form - his or her desires as to what should be done to him or her and what shouldn't. In a situation in which the choice is whether to continue or to stop the treatment, the patient's personal preferences are discussed at a very early stage. The other option is to have a name written down in that document, for identifying the person who will make these decisions for the patient, to avoid disagreements among family and friends that would place doctors in a position of having to decide and judge for themselves whose opinion to consider. How do you find it easier to implement: letting people make these choices while still healthy by filling in some forms or deciding on a person who has the right to make these decisions for them in the event that they are unable to do it themselves?

Mari Lõhmus: I find that these could be combined as well.

Teija Toivari: Yes, and it would be good simply because if the person made the decisions a long time ago, thoughts may change over time. When the person also adds the name of a loved one, the person selected probably knows the patient's life at that moment and what kind of decisions he or she would make.

Liidia Meel: The loved ones named in such wills are also the keepers of the document in, for instance, England, meaning that they get a copy of the paper.

Helgi Kolk: We should definitely have it in the e-health system. While in oncology a decision doesn't need to be made in a single day, in surgery it is very common. An increase in the number of 80-year-old and older people is clearly visible in Estonia, and the absolute number of people more than 85 years of age is constantly growing. The usual number of patients in our ward is 40. Sports and work traumatology cases are not as common as they used to be. Traffic accidents have gone down as well. In the 1990s, we had 400 traffic deaths per year; now it's 60-70 (the number of people injured is pretty much the same). The elderly have offset the difference. The number of people with trauma necessitating hospitalisation is the same as 20 years ago.

Tarvo Puri: So some sorts of documents are used among Jehovah's Witnesses. In addition, I learned from what you were saying that patients in grave condition are being talked to. The options are being discussed. Is there something of these discussions or documents that can be seen in the Patient Portal?

Mari Lõhmus: All our oncological decisions are made by a consilium ${ }^{* 6}$. This is also how we try to make decisions on stopping treatment. Our technological problem is that the consilium decisions that direct a patient to symptomatic treatment ${ }^{*} 7$ never end up in the e-health system. They are visible only in our hospital system.

Helgi Kolk: Are the patients present at these onco-consilia?

Mari Lõhmus: No. The situations in which a symptomatic-treatment decision is made can vary greatly in medicine. The decision may be made in conversation between a patient and a treating physician, taking into account the patient's preferences and the recommendations of the doctor. However, it can also be a medical consiliary decision of which a treating physician notifies the patient. Patients' general condition and state of consciousness can vary from good to very bad, so discussing all the aspects with them may not always be possible.

Tarvo Puri: Has anyone from this consilium talked to the patient first?

Helgi Kolk: Yes, the treating physician.

Mari Lõhmus: There are also some rare cases in which we go and stand next to the patient's bed with the entire consilium and make the decision there.

Tarvo Puri: It seems to me as a lawyer, as a person from outside, that if one of the consilium members has spoken to the patient and communicates to everyone the patient's wishes, it makes perfect sense.

Mari Lõhmus: It might not all be patient's wishes. This is [also from] the clinical ${ }^{*}{ }^{*}$ situation, those clinical data based on which the decision is made.

Tarvo Puri: But as part of that there is also the patient's own point of view.

6 An assembly of several types of specialists to determine a diagnosis and decide on treatment. A multidisciplinary oncological consilium consists of a surgeon, chemotherapist, radiation therapist, radiologist, and pathologist.

7 Treatment that relieves symptoms in a situation wherein treatment specifically to counter the illness itself has been stopped.

8 Health data based on analyses and the condition of the specific patient. 
Helgi Kolk: It remains relatively unsubstantial.

Mari Lõhmus: It may remain completely unsubstantial. The patient may refuse to accept a decision to stop the treatment. When it is clinically impossible to treat the patient, that doesn't mean we completely end all treatment. It means that the oncospecific treatment / anti-tumour treatment stops, but we will still continue with pain relief ${ }^{*} 9$, supporting treatment ${ }^{* 10}$, infection treatment, etc.

Teija Toivari: Just a thought that could maybe be taken into consideration in Estonia: We were visited by a palliative-care physician from Scotland who gave a really thorough presentation about it actually being good to be able to include the patient in the decision-making process. Never mind that it might be clinically clear as day that there is no point in continuing with the treatment. But from the viewpoint of that person, it is extremely important to be included in the decisions made at the end of life.

Liidia Meel: The problem is that for patients in a crisis situation when certain events take place around them, whether pathological or something else, they may not always be able to grasp the information shared with them, because both people and situations are different. They are often unable to even record that information in their brain. There have been tests with shared decision-making that includes the patient in the consilium. In comparison with the regular situation in which the patient is consulted with before and after the consilium meeting, the patients who could take part in it were significantly better informed and understood their situation and the options lying ahead much better.

Teija Toivari: I completely agree with that. When we started with the hospice, most of the patients didn't even know they had cancer, let alone that their active treatment had been stopped. Now things have changed - in recent years, legislation has come to require informing the patients of their situation. Most of them know if they have cancer, for example. Some of them also know when the specific treatment was stopped, while for some of them it has somehow remained unclear. But the way of receiving the information has a huge impact. When it comes from somewhere above - this is it; treatment stopped, and nothing will be done - the patient loses hope. When they have months to live, we try our best to rebuild that hope again: they still need to live right now. From the perspective of the person's quality of life at the end of life, it would be very good to have him or her involved the entire time.

Liidia Meel: I would like to add from the point of view of various specialists that, when speaking of documents and forms, we cannot talk about just one document, containing the right answers - patients wish to discuss these topics on different levels. It is about not just the physical aspect or social relationships but also existential and spiritual matters.

Tarvo Puri: For a moment, let's still take an example of a patient who would like to receive no medical treatment - the patient has decided not to let the pain and suffering be protracted. Let's assume we have a consilium. Would it be asked in that consilium meeting whether any of us has talked to the patient to see what he or she thinks of continuing the treatment? Maybe the patient doesn't want to be treated.

Helgi Kolk: I take part in two consilia. In the orthopaedia consilium, many of the people among the deciders are residents who do not actually express their opinions. A patient enters the room full of people in white coats and gets to ask questions. The patients usually have someone with them. The decisions are discussed and accepted very well. But the decisions of the onco-consilium when they are not actually about stopping treatment but all about the treatment itself - whether to have radiation therapy or chemotherapy, or on what to start, when, and where - are much more difficult to deliver to patients. After the consilium meeting, the patient may have already left the hospital, so I need to call the patient or family members or the family doctor. This situation is much more complicated. When the person is right there with us, we often ask him or her to disrobe. We think that this situation is uncomfortable for the patient. In reality, however, patients accept it happily when they see the process of making the decision. Take, for instance, a decision not to operate on some sort of large bone deformation. One leg is much shorter than the other and it is very difficult to walk, but here's the decision: we can't fix this. The decision was taken by this consilium. Not just a phone call from a doctor who took part in that onco-consilium that may have had many more bright heads in it, while the patient has no idea of how the decision was reached. This is a really important aspect emotionally as well.

Tarvo Puri: These discussions held with patients should still be visible somewhere - one day, one week, or a month later. I understand from your words that there is no database that shows the patient's own decisions.

9 Medicinal treatment that relieves pain; in certain cases, also palliative radiation treatment or nerve-blocking medicines.

10 Making a decision together. 
Helgi Kolk: There is. We have a sort of patient logbook both in the hospital and with outpatient treatment ${ }^{* 11}$ where we can write anything we'd like. Another issue is that the visiting time is 15 minutes. You use that 15 minutes to deal with the patient. Later, when you enter these things in your own free time, you remain quite laconic, adding just the main points. And the things that are not quite so necessary or traditionally added just remain inside your head.

Tarvo Puri: Could it, as a matter of course, contain a remark that the patient does not wish to receive treatment? Would that be taken into consideration next time?

Helgi Kolk: Sure.

Mari Lõhmus: We write such things down. The time factor plays a similar role in our consilium as well. A consilium definitely means much more to a patient when the patient attends as well. But if there are 20 [patients] attending in one day, all taking their clothes off and wanting to see their pictures, plus questions from relatives... From a human point of view, it is very important to explain these things and to do it calmly, but in the consilium we often don't have time for such thorough explanations. This is why consilia in increasing numbers take the path of inviting fewer and fewer patients to the meeting, and decisions are made on the basis of data or in accordance with a physician's judgement.

Liidia Meel: How much information can patients psychologically take in and commit to memory at once? Crisis theories suggest that it would be better to have another person with them who would help them remember and would explain things later. How about involving support specialists so that each consilium would also have a psychologist, a social worker, a religious minister, or (for example) a nurse or counsellor who would later take this patient, sit down with him or her, and go through these points one more time?

Mari Lõhmus: Some people in consilia have tried that, and the results have been very positive.

Teija Toivari: This also seems like a good idea in the sense that if a patient states a wish, we would not write down something that is based on a single emotion. When something has been said that is based on the current emotion, it might change, but when it has already become recorded somewhere, everyone would think it to be the final decision and treat it accordingly.

Tarvo Puri: The possibility of amending and changing is important with living wills too. Would something that was written down for the future at the age of 58 still be valid in two or three years? If a space or register were to be made for living wills for all the doctors to see, it would have to include a timeline, because the most recent one is the one that is valid. Do you feel the same?

Helgi Kolk: Absolutely. In England, there is a version that is revised every two years or so. It may also be done at an arbitrary time - for instance, in the case of a new disease or any other problem. You can always change it; it's not written in stone.

Tarvo Puri: Does the current system of taking notes or writing down information enable seeing some sort of sequence as well, for knowing that the information I am seeing is the most recent, not what the person expressed once a long time ago?

Helgi Kolk: The current Patient Portal is slightly primitive. Many things are not visible directly when one opens it, the content, etc. You have to click through a million visits and names, and it is very hard to understand where the important stuff is. Digging through that takes a lot of time. If it had a slightly better structure, finding important things would probably be easier, but right now it's like being a coal miner.

Teija Toivari: Yes, it should contain the most up-to-date information possible, made available somehow.

Tarvo Puri: But let's move on to examples in which a person interacts with his or her legal representative and discusses these issues, whether it's a lawyer or a notary. In many countries, there are just two witnesses who sign the living will. Do you feel that in a situation wherein these decisions have been discussed but with not a doctor but a person in a completely different field, something might go differently? For instance, a physician receives this document but the information is not clear or understandable, even though it has been discussed with a lawyer or witnesses beforehand. Something gets lost in translation...

Liidia Meel: That's the difference between interdisciplinary and multidisciplinary communication. When everyone acts alone, something like this may easily happen. An interdisciplinary approach requires various specialists to communicate with each other and reach decisions together.

Tarvo Puri: There are probably some forms or models that can be found abroad. Would these help? It could avoid loss of information, delivering it incorrectly or insufficiently.

11 Polyclinic visits. 
Teija Toivari: I find that there should definitely be medics to consult, because they are able to tell the presumed consequences of this or that decision. Otherwise, a question may remain as to whether the patient has been sufficiently informed.

Helgi Kolk: It would be like the decision of Jehovah's Witnesses who are adamantly against something without being able to see the possible consequences.

Tarvo Puri: Rainis Int has prepared at least one living will. Maybe you could tell us the story of that person? He was of quite advanced age, and I understand that his desire was to be completely free of any medical treatment, because he considered himself ready to leave this world when his time comes.

Rainis Int: The person who made this living will was born a few years after 1940, if I'm not mistaken. So not the oldest of people. According to him, he doesn't have any illness that could take him from this world any time soon. His philosophical background was that he didn't want to live hooked up to a machine and as a burden to everyone. His children are abroad, and his wife was already over 90 years old. So his point was that if something happened to him... He was a supporter of active euthanasia and would have liked it to be legal in Estonia.

Tarvo Puri: The document expressed a wish not to be treated, under any circumstances.

Rainis Int: Yes. Besides me, a lawyer and a doctor were involved in compiling this document. It contained a whole list of medical services he was not to receive, such as blood transfusions, mechanical ventilation, and a feeding tube. It also included medical services that I as a notary would never have been able to suggest [listing]. When a person visits [...] with a wish for a living will, I as a notary can't even name the medical services to refuse. We prepared the sample in co-operation with a doctor. It listed the services he may not in any circumstances be provided with. We emphasised that in his case, only palliative treatment methods should be used and implemented.

Tarvo Puri: Did you discuss how to make this visible?

Rainis Int: We understood that the Patient Portal, e-health, and whatever these tools are certainly are looked at by doctors. That was the impression we received.

Helgi Kolk: Yes, so it is.

Rainis Int: Then we couldn't provide any solution other than to make a list of all the medical institutions where he might end up in Estonia, and send them the document.

Helgi Kolk: How does it reach the doctor on call?

Tarvo Puri: Let's assume he has gone to a doctor with some sort of health problem and the paper has reached the doctor. Would it currently be honoured that he wants no treatment?

Helgi Kolk: I guess it depends on the situation in emergency cases. As you describe it, he's in his 7os. If he had an acute myocardial infarction ${ }^{* 12}$ in Estonia, it is completely treatable even if he has stated his wish not to be treated. So it still depends on the situation.

Teija Toivari: Maybe he should carry that paper with him as well? If he has an accident, an ambulance crew would come and rescue him, and he would remain in that state and be taken to hospital. From there on, he would remain in a vegetative state. ${ }^{*}{ }^{3}$ Actually, his wish should be known already at the moment the ambulance arrives.

Rainis Int: Yes, we talked to him about this. He has that paper at home. The question was, rather - he himself said that his wife is a devout Christian - whether this paper would be displayed at the right moment. He wasn't sure about his wife and suspected that she might try to hide his document.

Helgi Kolk: Although a doctor helped you identify the institutions and procedures during compilation of this document, there is also a need to evaluate the mental state of the person who is making such a statement. This is a medical issue as well: to find out whether he isn't, in fact, deeply depressed and preparing the document because of that.

Rainis Int: Part of the work of a notary is in considering a person's legal capacity and capability of exercising will. In that sense, he passed the test. But, of course, the issue with notarial work is that we are not psychiatrists and are unable to tell such things with $100 \%$ certainty. There are probably some nuances through which we could be tricked. The mini mental test ${ }^{*}{ }^{*}$ may not always give the right answer.

\footnotetext{
12 A heart attack.

13 A condition of severe brain damage in which the person is awake and retains the ability to breathe, open his or her eyes, and maintain blood circulation independently but has no reaction to outside stimulation.

14 The Mini Mental State Assessment, a short-form test assessing a person's cognitive capabilities.
} 
Liidia Meel: There are various levels on the basis of which it should be assessed. It's not only psychological or psychiatric. The decision may also be born of social conditions, for social reasons. It may have religious grounds. Therefore, various specialists should be involved, to enable delving deeply into these matters. I believe that the system in England requires the living will to go to the family physician firstly, then to the treating physician, and then to their electronic system similar to our e-health. It is up to the person to decide whether he or she wants it to be added there. People can also carry it with them, and there's one copy at home. Additionally, it is sent to the people the patient has specified. Not that a Christian wife at home gets to decide whether to show or not show this paper. The persons the patient him- or herself has trusted are probably more reliable and will really produce that paper in case it's needed.

Helgi Kolk: Yes, but they may not be there when he's resuscitated at home.

Tarvo Puri: I understand that in your opinion, the surest way would be for a doctor to discuss it with the person. Physicians can also describe the perspectives and assess what the modern treatment options are in certain conditions and situations.

Liidia Meel: A doctor should work with other professionals, because they probably don't have enough time to maintain competency in every field.

Teija Toivari: Regrettably, there is another issue that arises here, because our social-welfare system is still largely undeveloped in several ways - it may be too economically burdensome for children and grandchildren to take care of their elderly relatives. These may be considerations in the background. It is a painful topic and should be effectively dealt with.

Helgi Kolk: Exactly. 'There's no money for a care home; no-one can afford it. Please just give me the shot.' Who hasn't heard that?

Rainis Int: In this case, I didn't ask for anyone's bank statement.

Tarvo Puri: The next topic might be a bit more in lawyers' field of expertise. What is the current understanding or knowledge among doctors: is it necessary to make any changes and improvements to our legislation if living wills are even to gain ground in Estonia or to enable them to be taken into consideration?

Helgi Kolk: Definitely. It has to have legal power. Otherwise, it's difficult to consider accepting some kind of paper or entering something in the digital health file when it's not even legal in Estonia. In that case, a corresponding section would be added. At the moment, there is a section of the digital health file that turns red if the person carries a dangerous microbe or has an allergy. It should go red also in the case of the person having made a certain decision. It would be visible straight away if he or she is being admitted somewhere, even to the ER. Once again, chronic issues allow some time, while the most challenging situations are the ones in which a decision is made very quickly. It's just as you said before: the patient may ultimately be in a vegetative state after resuscitation, but we'd have no way of taking back what's been done.

Mari Lõhmus: Having a document is important not only for the people who are ill but also for the ones who are healthy. They should be able to take some time and think about what they would prefer, in case something happens.

Tarvo Puri: It seems that the legislation is perfectly ready to enable medical professionals and lawyers to consider living wills. Rather, it's the practice that has got stuck somehow or is waiting for the next generation. Making the information easily visible and displayed via the Patient Portal or e-health system upon logging in is what needs regulating. Perhaps there should also be a norm as to whether it may be a decision taken by the person alone or instead there should be confirmation by a doctor, two witnesses, and a notary. It is important for the person to understand the consequences of the action and the decision while deciding.

Helgi Kolk: However, what is the legal force? As a compiler, I could write anything I want in it. As a doctor, am I obliged to follow it?

Tarvo Puri: The current legislation - that is, the overall rule - states that health services are to be provided only upon the consent of the patient. There are also some specifying clauses - for instance, if consent can be found somewhere in the past, that too must be taken into consideration. Living wills would actually fall under that clause. The system of making these consent items visible at the most important moment, the time when they are necessary, is the unsatisfactory or faulty part.

Rainis Int: Speaking about the document we wrote, we didn't title it a living will. It was a statement for refusing health services. We used the Law of Obligations Act terminology that refers to the criteria for the provision of health services - that is, when a patient may be provided with such services. So yes, we didn't call it a living will, and there is no such term in the currently valid legislation. There is no such term. The document we made was titled 'Statement for Refusing Health Services'. 
Helgi Kolk: In the current context, that's even easier to understand. Working in this area and seeing a document like this, you understand that it has relevance.

Mari Lõhmus: If the question is the format or who should sign the document, I would find it helpful to have some sort of blank or form that covers the most common cases, then an additional field for filling in by the patient, for what he or she would want to be done and what would be out of the question. Who should be involved in this process? I think that, in addition to the patient, there could be medical and, as emphasised several times already, psychosocial help, religious help or counselling, and lawyers. There should also be a loved one or contact person [nominated].

Liidia Meel: Just recently, I happened to read an article about the experience in the Netherlands. If a person expresses - as we said before - a death wish, this can be understood at different levels of intensity, from being suicidal and wanting to end one's life to just having an outlook associated with a serious illness, wherein abandoning life or dying in consequence of refusal of treatment would allow escape from a difficult situation. In this case, the situation is not just physical symptoms and the reason is not just reluctance to become a burden to someone; there are other levels as well. One of them is that of perceived value, dignity. That particular article made a suggestion. There may be different types of counselling, in different areas, but this article dealt with 'dignity therapy', which is a form of psychotherapy. This particular patient made an about-face on refusing treatment because of having had a chance to talk about heartfelt values, to discuss them, and to get in touch with his or her so-called core identity - who one is and why one should stay here for a little while longer. Hence, this is not just physical.

Helgi Kolk: Where has this topic come from anyway? Why wasn't it already being discussed long ago? It has been under discussion for about 50 years, maybe, but not much longer. It has arrived with huge medical progress that lets people stay alive who no longer have a mind of their own or ability to express themselves via speech. That is the source of all this.

Mari Lõhmus: In medicine, it is sometimes easier to treat than to stop treatment. It is easier to continue with endless treatment than to make the decision that it is no longer in the interests of the patient.

Helgi Kolk: At the same time, it's a huge burden on resources, especially in oncology, where treatment can be extremely expensive, but also in other ways. Palliative care long ago ceased being just for cancer patients in Europe. It is care for all terminal patients ${ }^{* 15}$ or for people who are about to die. No doctor can tell you whether you have two weeks or two months left. Sometimes there can be surprises. In any case, palliative care is a broader concept that extends not just to oncological patients but also to elderly dementia patients, for example.

Teija Toivari: Yes, treatment can bring a lot of suffering. I see probes the most in my work. ${ }^{*}{ }^{16}$ And, in the end, there are bedsores that may last for months.

Tarvo Puri: The overarching idea of this whole conversation, of the article and with the entire topic, is that a person should have the opportunity to discuss these things while still capable of doing so. In my work and here in this discussion, I can see that the other party needs time for this. You also said that there is 15 minutes per person and many people get handled by a consilium in a day. It's the same for lawyers - we don't have a whole day or even half a day for each client. But, as you pointed out, in many cases, if we or the doctor had this time, the individual's attitude could change completely. The person finds the value or makes decisions in full awareness of their implications.

Liidia Meel: In one palliative-care concept, the care does not start in the terminal phase. Palliative care should, in a way, start already with the diagnosis and increase gradually as the proportion of active treatment decreases. Co-operation of an interdisciplinary treatment team is part of palliative care. Here's where the time factor comes in. If someone starts getting this kind of treatment at the very beginning, it is clearly more likely for the end-of-life wishes to become better known over this time. I visited a hospital in England and saw how such co-operation took place there. All these decisions and discussions, the values that are summed up and the important aspects being brought out, are somehow gathered together so that the data can be accessible later. It would take some time, but if this team would work that way here as well... North Estonian Regional Hospital is a good example with its palliative-care team, but PERH is not the only hospital in Estonia. If it were to begin like that, already in the early stages, we would have more time.

15 A person in the final stages of life, a dying patient.

16 Tubes inserted through the nose, the mouth, or skin of the stomach to feed the patient or supply/remove fluids. 
Tarvo Puri: The time spent on discussion will pay off at a later stage, when it's necessary to decide whether or not to continue treatment: you would no longer need to expend this resource that could go to waste, because everything has been discussed already.

Helgi Kolk: Another important issue in Estonia is the need to place people under guardianship if they no longer have capacity to exercise will. Doctors have not diagnosed dementia very well in Estonia - various diseases are lumped together as dementia. Therefore, there are no diagnoses and is no way of placing the patient under guardianship. Then, when these unfortunate elderly people end up in the medical system, our hands are tied.

Tarvo Puri: Guardianship could be easily replaced by a document in which the patient states the name of a person authorised to make decisions for him or her, so that there would be no need to communicate with all the relatives.

Helgi Kolk: We usually call one. That's often the only contact we have. But, as I said, for example, also other contact persons appear and express their wishes and opinions, and they are often unable to reach agreement.

Tarvo Puri: But for people to even know that such a contact person can be registered requires a bit of PR activity and distributing the information through the media.

Helgi Kolk: At present, there is a compulsory section in medical records: contact person. Often it's just a phone number. I call them and let them know that their phone number is in this person's medical history. I ask who the person is to the patient. That's how I start. No name, no affinity or anything, just a phone number.

Tarvo Puri: Do ambulance workers too see this?

Helgi Kolk: Yes.

Tarvo Puri: So this is currently the most accessible information in the entire e-health and Patient Portal system - someone's phone number.

Mari Lõhmus: All cases are separate in the Patient Portal. This means that if the patient has been to a clinic, there may be one piece of contact information, and if the patient has been dealt with elsewhere, the information may be different.

Helgi Kolk: It's on the cover of every health file. For example, someone brings a neighbour to a hospital. That person's phone number is taken by the reception staff. They don't even ask who this person is to the patient. The reception-desk worker will write down the number. At the moment, there is no information as to what that number means.

Mari Lõhmus: Maybe the ambulance personnel take a phone number as well?

Helgi Kolk: Yes - for example, the person who summoned an ambulance... When a random person finds someone on the street and calls an ambulance, the ambulance will get that person's phone number.

Tarvo Puri: From a broader perspective, making patients' wishes or even their contact person, that single contact person, visible brings on a set of relatively complex technical issues.

Helgi Kolk: It probably requires some PR to make people more responsible in this regard. The information is not available to people at present. I have seen for myself how a registrar asks for a phone number and there's absolutely no difference what number you give. Often, the number isn't even in use or a completely random number is given. You make a call, and it turns out to be a wrong number. This could start functioning within the current system if it were to receive more meaning than just a number.

Tarvo Puri: What if a doctor calls that number and the person picking up the phone says that 'yes, I know this person, and they told me they don't want to be treated'? Once again, the question is what I asked in the beginning: Let's say that you as a medical professional can tell that it's highly unlikely we could make anything better for that patient. Would the reply received affect your decision?

Helgi Kolk: I think it would, but normally I have tried to handle the situation by inviting the person to the hospital so that I can see who this person really is. I can't let the words of a person on the phone determine someone's destiny when I don't even know who that person is.

Tarvo Puri: We have, more or less, covered everything we planned to discuss. The general consensus is that the legislation needs to be more specific in order to take the patient's wishes into consideration. The technical side needs perfecting and specifying, so that every doctor who has to make these decisions could see clearly in the foreground (against all the other information) whether the person has expressed his or her wishes or provided a name of someone to make that decision. Also, PR activity is needed for guiding people to think about these things and make decisions. 